\title{
The effect of I-amino acid oxidase on hep-2 squamous cell carcinoma cell line
}

\begin{abstract}
Introduction: Head and neck squamous cell carcinoma (HNSCC) is responsible for more than $90 \%$ of head and neck cancers. L-amino acid oxidases (LAAOs) are extensively distributed in the following families of venomous snakes: the Viperidae, Crotalidae and Elapidae families. A number of proteins related to LAAO activity have been found to manifest anti-neoplastic, antimicrobial or apoptosis-inducing activity. It can be assumed that that the general mechanism of LAOO toxicity is determined by the generation of cytotoxic $\mathrm{H} 2 \mathrm{O} 2$ in varying amounts. In short, the aim of this study is to ascertain the anticancer effect, by way of flowcytometry and real-time PCR, of LAAO on the HEP-2 cell line after 24 hours, 48 hours and 72 hours.
\end{abstract}

Materials and methods: Once theHEP-2 cell line was propagated and LAAO was added to the culture medium, the cells were analyzed after 24 hours, 48 hours and 72 hours.

Results: The results of this analysis reveal that LAAO was the root cause of apoptosis in the HEP-2 cell line. In addition, the apoptosis percentage was directly related to time. The p53 expression increased by time, and the inverse was true for bcl 2 expression.

Conclusion: The results reveal that LAAO has a substantial effect on the anticancer activity of the HEP-2 cell line.

Keywords: squamous cell, advancements, treatment, surgical, death, mortality rate, chemotherapy, standard, radiation, significant
Volume I Issue I - 2017

Wael Elias Y,' Mohamed Ayoub S, ${ }^{2}$ Moataz El Kholy M, ${ }^{3}$ Hossam El Malahy, ${ }^{4}$ Khalid Merdad $A,{ }^{5}$ Rayyan Kayal A, ${ }^{5}$ Helal Sonbul $M^{5}$

'Departmnet of Oral diagnostic science, King Abdul Aziz University, Saudi Arabia

${ }^{2}$ Faculty of Dentistry, King Abdul Aziz University, Saudi Arabia and Ain Shams University, Egypt

${ }^{3}$ Department of Oral and Maxillofacial Surgery, October University for Modern Sciences and Arts (MSA), Egypt ${ }^{4}$ Faculty of Dentistry, Ain Shams University, Egypt

${ }^{5}$ Faculty of Dentistry, King Abdul Aziz University, Saudi Arabia

Correspondence: Wael Y Elias, Associate Professor \& Consultant in oral and maxillofacial pathology, Chairman, Department of oral diagnostic science, King Abdul Aziz University, Faculty of Dentistry, Jeddah, ext: 20467, Saudi Arabia, Tel 0096626401000,00966538249777,Email welias@kau.edu.sa

Received: October 26, 2017 | Published: November 07, 2017
Abbreviations: HNSCC, head and neck squamous cell carcinoma; LAAOs, 1-amino acid oxidases; MMPs, matrix metalloproteinase's; VEGF, vascular endothelial growth factor; EGF, epidermal growth factor; PS, phosphatidylserine

\section{Introduction}

Head and neck squamous cell carcinoma (HNSCC) is responsible for more than $90 \%$ of all head and neck cancers. ${ }^{1}$ That said, despite advancements in treatment and surgical reconstruction, the corresponding mortality rates have shown no improvement in the past forty years. Even with standard treatment options in therapies such as radiation, surgery and chemotherapy, HNSCC patient's face a $60 \%$ mortality rate. ${ }^{2}$ Cancer treatment continues to pose a significant challenge, as cancer is one of the world's leading causes of death. ${ }^{3}$ In terms of the therapeutic management of different types of cancers, the poor outcome is partially the result of their aggressive nature, the defense host mechanism and their metastatic potential. Chemotherapy, radiotherapy and surgery offer inadequate protection, as they affect both normal cells and cancer cells. ${ }^{4}$ Curing cancer by way of natural products (meaning plants and animals) has been practiced for more than a century now, and the use of purified chemicals in order to treat cancer remains prevalent today. ${ }^{5}$ The development of novel targeted anticancer therapies ${ }^{6,7}$ are largely the result of the signaling pathways and molecular mechanisms that are involved in oncogenesis. While a number of these agents serve as inhibitors against the vascular endothelial growth factor (VEGF), epidermal growth factor (EGF) and matrix metalloproteinase's (MMPs) receptors, others promote apoptosis. ${ }^{8}$
Apoptosis is a highly regulated type of cell death that is instrumental in the development and maintenance of higher organisms. Defined by such morphological and biochemical hallmarks as phosphatidylserine (PS), exposure to the outer leaflet of the plasma membrane, nuclear condensation and chromatin cleavage into oligonucleosomal fragments, ${ }^{9}$ apoptosis tends to occur during development and aging. In addition, it serves as a homeostatic mechanism that maintains cell populations in tissues. Apoptosis can also be a defense mechanism that occurs during immune reactions or in cases where cells are damaged due to disease or noxious agents. ${ }^{10}$ Snake venom consists of a complex combination of pharmacologically active substances, including metalloproteases, ${ }^{11}$ phospholipases A2, ${ }^{12}$ serine proteases ${ }^{13}$ and other enzymes. Not only can it induce tissue damage, nausea, vomiting and sweating, but snake venom can lead to bradycardia, hypotension, and shock and in severe cases, death as a result of the hemorrhagic, coagulant and neurotoxic activities that occur due to the behavior of these pharmacologically active substances..$^{14} \mathrm{~L}$-amino acid oxidases (LAAOs) are extensively distributed in the following venomous snake families: the Viperidae, Crotalidae and Elapidae families. ${ }^{15}$ In certain snake species, L-amino acid Oxidase (LAAO) represents up to $30 \%$ of the total venom proteins. ${ }^{16}$ Thus, various studies were conducted with LAAO to determine its behavior and activity in vivo. Wie et al. ${ }^{17}$ induced paw edema in mice after injecting them with $5 \mu \mathrm{g}$ of LAAO ${ }^{17}$ Moreover, LAAO can induce hemorrhage, ${ }^{18}$ which can lead to systemic effects like renal toxicity. ${ }^{19}$ Despite its toxicity in vivo, LAAO is not lethal when injected in the amounts of $120 \mu \mathrm{g} / 30 \mathrm{~g}$ in Swiss-Wistar mice. ${ }^{20}$ In vitro studies concerning LAAOs revealed antibacterial properties, ${ }^{21,22}$ Leishmanicidal activity, ${ }^{23}$ trypanocidal activity, ${ }^{24}$ toxicity upon entering the cancer cell lines ${ }^{25}$ and the 
induction or inhibition (or both) of platelet aggregation. Studies revealed that these effects are closely related to the production of $\mathrm{H}_{2} \mathrm{O}_{2},{ }^{21}$ as the correlation is apparent.

\section{Materials and methods}

\section{Materials}

a. Squamous cell carcinoma cell line (HEP-2) was supplied by the Cell Culture Department at VACSERA in Cairo, Egypt. HEP-2 cells were supplied by the "American Type Culture Collection" (ATCC) in the form of a frozen vial (reference number "HTB96").

b. L-amino acid Oxidase (LAAO) served as a cytotoxic drug throughout this study. The drug was purchased from Sigma Aldrich in the United States.

\section{Methods}

Tissue Culture Technique was performed at the Applied Research Unit, VACSERA, and Cairo, Egypt.

Propagation of the HEP-2 cell line: Human laryngeal squamous cell carcinoma $\left(\mathrm{HEp}^{2}\right)$ cells were acquired from VACSERA ${ }^{\circledR}$ and grown in a sterile tissue $50 \mathrm{~cm}^{2}$ flask in a complete medium that contained Dulbecco's modified Eagle's medium (DMEM), with a supplement of antibiotics (100U/ml penicillin and $100 \mu \mathrm{g} / \mathrm{ml}$ streptomycin) and $10 \%$ fetal bovine serum (FBS) in $95 \%$ air, $5 \% \mathrm{CO}_{2}$ at $37^{\circ} \mathrm{C}$ (Figure 1). According to the time interval of 24,48 and 72 hours, the cell line was propagated and subdivided into three separate groups.

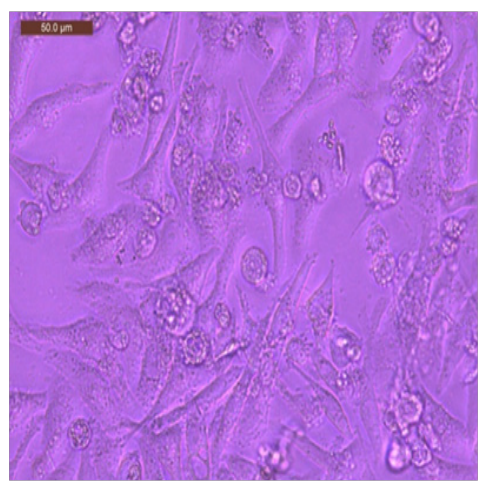

Figure I Propagation of the HEP-2 cell line.

Cytotoxicity determination by MTT Assay: This helped to determine the concentration of LAAO, which permitted $50 \%$ viability of the cells.

Assay protocol: In $100 \mathrm{ml}$ of culture medium, HEP-2 cells were cultured in a flat-bottomed 96 well plate (tissue culture grade). During the process, the MTT reagent was added $(10 \mathrm{ml}$ per well), while the plate was incubated for three hours. In an effort to solubilize the Formosan dye, detergent reagent was added to each well before measuring the absorbance of the individual samples in a micro plate reader at 550$600 \mathrm{~nm}$ (based on the filters available).

Based on the following chart, the LAAO concentrations that permitted $50 \%$ viability of HEP- 2 cells were:

1) $25 \mu \mathrm{g} / \mathrm{ml}$ at 24 hours.

2) $12.5 \mu \mathrm{g} / \mathrm{ml}$ at 48 hours.

3) $3.125 \mu \mathrm{g} / \mathrm{ml}$ at 72 hours.
It was found in a pilot study that after 24 hours, the effect of the drug concentration was very strong on the HEP-2 cell line, while the opposite was true after 72 hours. (In other words, the effect of the drug concentration was very weak on the HEP-2 cell line.) Consequently, in this study, the optimal concentration of the drug is $12 \mu \mathrm{g} / \mathrm{ml}$, or the concentration that permits $50 \%$ viability of the cells after 48 hours (Figure 2).

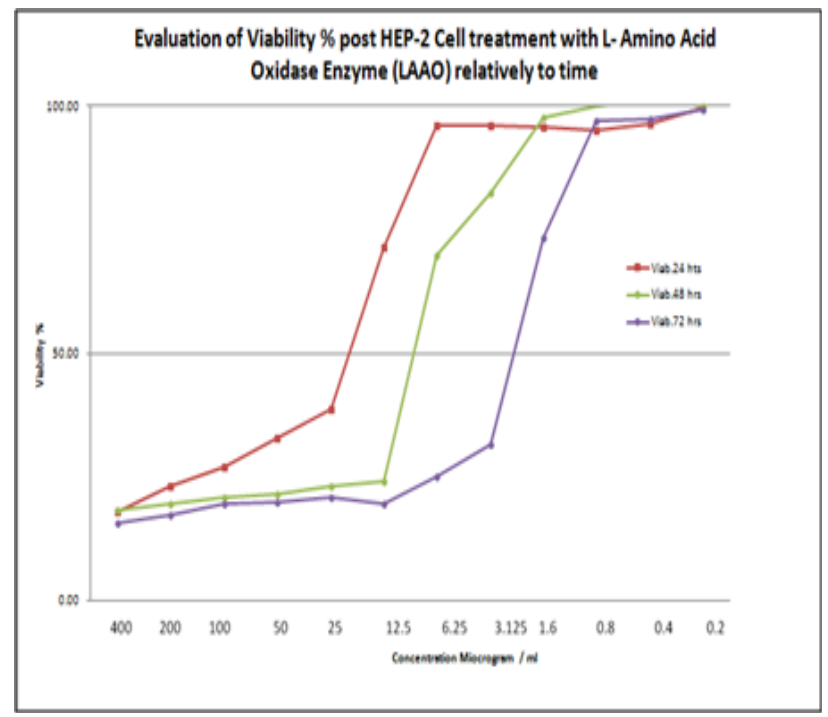

Figure 2 Consequently, in this study, the optimal concentration of the drug is $12 \mu \mathrm{g} / \mathrm{ml}$, or the concentration that permits $50 \%$ viability of the cells after 48 hours.

Treatment of the HEP-2 cell line with LAAO: The HEP-2 cell pretreatment consisted of a mixture of complete medium containing Dulbecco's modified Eagle's medium (DMEM), with a supplement of antibiotics ( $100 \mathrm{U} / \mathrm{ml}$ penicillin and $100 \mu \mathrm{g} / \mathrm{ml}$ streptomycin), $10 \%$ fetal bovine serum (FBS) and $12.5 \mu \mathrm{g} / \mathrm{ml}$ of LAAO for 24 hours, 48 hours and 72 hours. The HEP-2 cells were scrapped and centrifuged following treatment, while the supernatant was discarded and the cell pellet was stored in order to accommodate a flowcytometry analysis and real-time PCR assessment.

Flowcytometry technique: The ANNEXIN V-FITC kit is designed to detect apoptosis based on the binding properties of annexin $\mathrm{V}$ to phosphatidylserine (PS) and on the DNA-intercalating capacity of propidium iodide $(\mathrm{PI})$.

- The cell samples were washed with PBS. They were then centrifuged for 5 minutes at $500 \mathrm{xs}$ at $4^{\circ} \mathrm{C}$.

- The supernatant was discarded, while the cell pellet was suspended in binding buffer.

- $1 \mu \mathrm{L}$ of annexin V-FITC solution and $5 \mu \mathrm{L}$ of dissolved propidium iodide (PI) were added to the cell suspension and mixed gently.

- The tubes were stored in the dark and on ice for 15 minutes.

- $400 \mu \mathrm{L}$ of binding buffer was added and mixed gently.

- The cell preparation was assessed by way of flowcytometry.

\section{Real-time PCR}

\section{Extraction of RNA}

This was carried out with the GF-1 total RNA Extraction Kit 
purchased from vivantis technologies in the United States. The extracted RNA was stored at $-20^{\circ} \mathrm{C}$.

\section{Synthesis of complementary DNA (cDNA) by reverse transcriptase}

This was carried out through the use of the Revert Aid First Strand cDNA Synthesis Kit, which was purchased from Thermo Scientific ${ }^{\circledR}$ in the United States. The converted cDNA was stored at $-20^{\circ} \mathrm{C}$.

\section{Real-time PCR}

This was conducted through the use of Maxima SYBR Green qPCR Master Mix, purchased from Thermo Scientific ${ }^{\circledR}$ in the United States. The samples were placed in the machine (StepOneTM Realtime PCR system), and the thermal cycle was adjusted as shown:

One cycle of initial denaturation at $95^{\circ} \mathrm{C}$ for 10 minutes.

Forty cycles of:

i. Denaturation at $95^{\circ} \mathrm{C}$ for 15 seconds.

ii. Annealing at $60^{\circ} \mathrm{C}$ for 30 seconds.

iii. Extension at $72^{\circ} \mathrm{C}$ for 30 seconds.

\section{Calculation of Relative Quantification (RQ) (relative expression)}

Subsequently, the RT-PCR runs the data. The data is expressed in Cycle threshold $(\mathrm{Ct})$. The PCR data sheet features $\mathrm{Ct}$ values of the assessed gene $\left(\mathrm{p}^{53}\right.$ and $\left.\mathrm{Bcl}_{2}\right)$ and the housekeeping gene (also known as the reference gene, which is continuously expressed in the cell [beta actin]). A negative control sample was used to measure the expression of a specific gene. Then, target gene expression was assessed and analyzed in conjunction with the reference (internal control) gene by way of the following equation:

$$
\begin{aligned}
& \Delta \mathrm{Ct} \text { sample }=\mathrm{Ct} \text { assessed gene- } \mathrm{Ct} \text { reference gene } \\
& \Delta \Delta \mathrm{Ct}=\Delta \mathrm{Ct} \text { sample-Ct control gene } \\
& \mathrm{RQ}=2-(\Delta \Delta \mathrm{Ct})
\end{aligned}
$$

\section{Results}

\section{Flow cytometry}

Control group: Results showed that $92.3 \%$ of untreated HEP-2 cells were viable after 24 hours, while $7.69 \%$ of the cells showed early apoptotic changes. No late apoptotic changes or necrotic cells were observed. After 48 hours, $87.1 \%$ of the cells were viable cells, while $12.9 \%$ showed early apoptotic changes. Further, there were no late apoptotic changes or necrotic cells. However, after 72 hours, $73.9 \%$ of the cells of the HEP-2 cell line were viable, while $26.1 \%$ showed early apoptotic changes (Figure 3). No late apoptotic changes or necrotic cells were observed.

HEP-2 treated with LAAO: Results showed that $46.4 \%$ of HEP-2 cells were viable 24 hours after treatment with LAAO, while $53.2 \%$ of the cells showed early apoptotic changes and $0.3 \%$ showed late apoptotic changes. There were no necrotic cells. After 48 hours, $16.7 \%$ of the cells were viable; $83.2 \%$ showed early apoptotic changes. Late apoptotic changes were observed only in $0.8 \%$ of the cells; no necrosis was observed. However, after 72 hours, $8.4 \%$ of the cells of HEP-2 cell line were viable, while $91.6 \%$ showed early apoptotic changes. Moreover, there were no late apoptotic changes or necrotic cells (Figure 4).

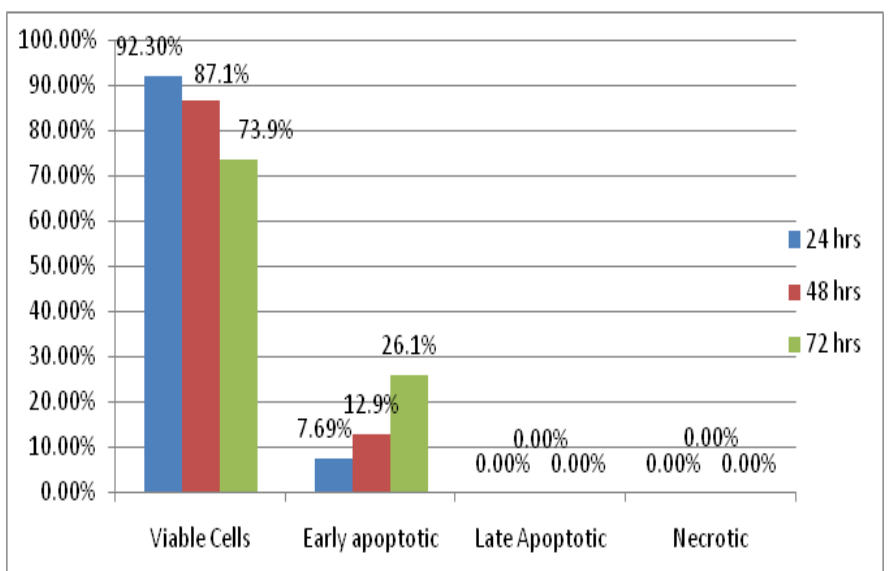

Figure 3 Chart showing the percentage of apoptosis in control group.

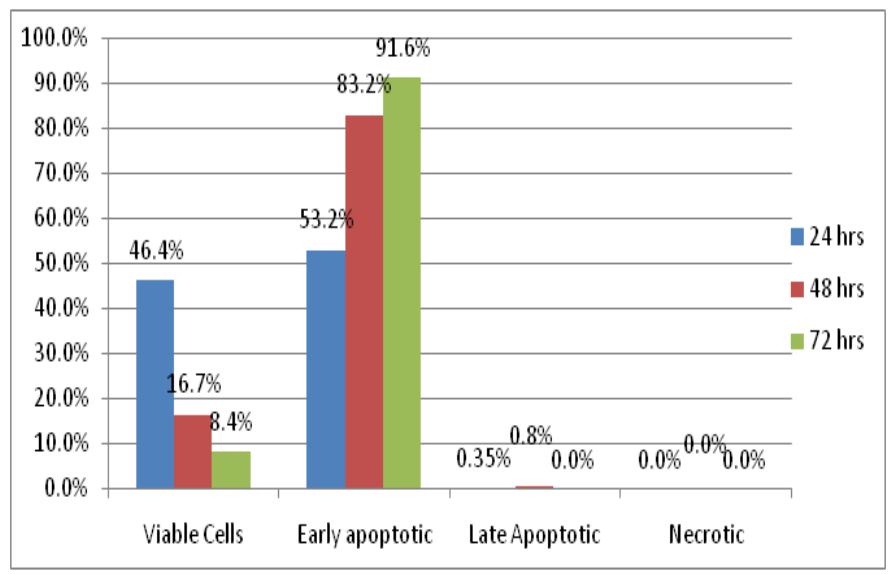

Figure 4 Chart showing percentage of apoptosis in HEP-2 cells after treatment with L-Amino Acid Oxidase.

\section{PCR results}

Expression of $\mathbf{p}^{53}$ : The expression of $\mathrm{p}^{53}$ was markedly increased after treatment of the cell line with LAAO when compared to the control group after 24, 48, and 72 hours.

Expression of $\mathbf{B c l}_{2}$ : The expression of Bcl-2 was markedly decreased after treatment of the cell line with LAAO when compared to the control group after 24,48 , and 72 hours.

\section{Statistical results}

The expression of $\mathrm{p}^{53}$ and $\mathrm{Bcl}_{2}$ was statistically significant in Group I after 48-hour treatment of HEP-2 cells with LAAO (Table 1).

Table I Expression of $\mathrm{p}^{53}$ and $\mathrm{Bcl}_{2}$ after treatment of the cell line with L-amino acid oxidases at 24,48 , and 72 hours I

\begin{tabular}{lllll}
\hline \multicolumn{2}{c}{ LAAO group } & $\mathbf{2 4}$ hours & $\mathbf{4 8}$ hours & $\mathbf{7 2}$ hours \\
\hline P53 & Mean & $1.33 \pm$ & $2.53 \pm$ & $2.05 \pm$ \\
& P-value & 0.30 & $.59^{2}$ & 0.71 \\
Bcl-2 & Mean & $1.16 \pm$ & $.57 \pm$ & $.59 \pm$ \\
& P-value & 0.54 & $.24^{2}$ & 0.26 \\
\hline
\end{tabular}




\section{Discussion}

With 600,000 cases per year and a 50\% mortality rate, head and neck squamous cell carcinoma (HNSCC) is the world's sixth most common type of cancer. ${ }^{3}$ In terms of HNSCC, tobacco use, alcohol consumption and infection with human papilloma virus (HPV) are all major risk factors. ${ }^{26}$ Regardless, even with advancement in our knowledge of HNSCC epidemiology and pathogenesis, the corresponding survival rates of most types of HNSCC have not shown any improvement in the last forty years. ${ }^{2}$ Cancer treatment continues to pose challenges in the world today, as cancer is still a leading cause of death across the globe. ${ }^{3}$ Recent insight into the apoptotic process has resulted in new parameters to detect and assess apoptosis. Among these parameters is the presence of phosphatidylserine (PS) on the surface of the cells. In the early stages of apoptosis, the cell membrane maintains its integrity, but the asymmetry of the cell membrane phospholipids becomes compromised..$^{4-7}$ PS is exposed at the cell surface and develops a specific signal for the recognition and removal of apoptotic cells by way of macrophages. ${ }^{5-8}$ Among the earliest signs of apoptosis is the loss of plasma membrane asymmetry. The membrane phospholipid phosphatidylserine (PS) is translocating from the inner leaflet to the outer leaflet of the plasma membrane in apoptotic cells, which exposes PS to the external cellular environment. ${ }^{27}$ In this study; we relied on an Annexin-V FITC kit as a means of detecting the percentage of apoptosis in the HEP-2 cell line. By using LAAO to treat the HEP-2 cell line, we were left with a higher percentage of apoptosis in the HEP-2 cell line than in other groups. The apoptosis percentages came in at $53.2 \%, 83.2 \%$ and $91.6 \%$ following 24 hours, 48 hours and 72 hours, respectively. This is the result of protracted exposure to high amounts of $\mathrm{H}_{2} \mathrm{O}_{2}$. Andes et al. ${ }^{9}$ and Samel et al. ${ }^{28}$ discussed that through the use of Jurkat and K562 (human chronic myeloid leukemia) cells, respectively, a low concentration of LAAO-induced apoptosis ensued, but led to higher concentrations of necrosis. Ande et al. ${ }^{9}$ determined that catalase and the remaining $\mathrm{H}_{2} \mathrm{O}_{2}$ scavengers abolished the apoptosis-inducing activity, which indicates that the $\mathrm{H}_{2} \mathrm{O}_{2}$ generated by LAAO activity plays a critical role in the apoptosis. ${ }^{9}$ Conversely, Suhrand Kim revealed that LAAOinduced apoptotic mechanisms were clearly distinguishable from the mechanism that is directly stimulated by exogenous $\mathrm{H}_{2} \mathrm{O}_{2}$. This suggests that LAAO-induced apoptosis was not triggered exclusively by the peroxide (which was produced by oxidation). ${ }^{29}$ However, demonstrated that venomous LAAOs bind directly to the cell surface and increase the local peroxide concentration as a result.

Disruption of $\mathrm{p}^{53}$ function leads to checkpoint defects, genomic instability, immortalization of cells and inappropriate survival. This allows for proliferation and continued evolution of damaged cells. Given the substantial advantage generated by the loss of the $\mathrm{p}^{53}$ function, it not shocking that $\mathrm{p}^{53}$ is the most frequently inactivated tumor suppressor gene that exists in human cancer. ${ }^{30}$ In this analysis, the $\mathrm{p}^{53}$ expression in HEP-2 cells increased following treatment by way of LAAO alone more than it did from other groups. The results revealed a direct relationship between $\mathrm{p}^{53}$ expression and time, while the inverse was true for the Bcl-2 expression in HEP2. After 48 hours, the expression of both genes became statistically significant. It has been confirmed that cases of severe oxidative stress compromise mitochondrial integrity, which results in the opening of the permeability transition pore, reduction in membrane potential, mitochondrial calcium overload and the degradation of the cell's energy metabolism, all of which culminate in cell lyses Ande et al. ${ }^{9}$ Described that when apoptosis occurs in Jurkat cells following treatment with LAAO, the condition is the product of an extreme oxidative insult that inundates the protective capacity of Bcl-2 and by passes the cell death pathway's critical control points. ${ }^{9}$ It could be concluded from the results of the present study that LAAO has a powerful anticancer activity on HEP-2 cell line.

\section{Acknowledgments}

I would like first to thank King Abdul Aziz University faculty of dentistry for all support it gives during my research.

\section{Conflict of interest}

Second, I want to declare that all authors of this manuscript have no conflict of interest.

\section{References}

1. Batsakis JG. Tumors of the head and neck: Clinical and Pathological Considerations. 2nd edition. USA: Lippincott Williams and Wilkins; 1979. p. 1-584.

2. Dimery I, Hong W. Overview of combined modality therapies for head and neck cancer. J Natl Cancer Inst. 1993;85(2):95-111.

3. Jemal A, Bary F, Center M, et al. Global cancer statistics. Cancer J Clin. 2011;61(2):69-90.

4. Gomes A, Bhattacharjee P, Mishra R, et al. Anticancer potential of animal venoms and toxins. Indian J Exp Biolo. 2010;48(2):93-103.

5. Newman D, Cragg G. Natural products as sources of new drugs over the last 25 years. J Nat Prod. 2007;70(3):461-477.

6. Yuan Y, Liao Y, Hsueh C, et al. Novel targeted therapeutics: Inhibitor of MDM2, ALK and PARP. J Heamtol Oncol. 2011;4:16.

7. Bhardwaj A, Singh S, Singh A. MicroRNA-based cancer therapeutics: Big hope from small RNAs. Mol Cell Pharmacol. 2010;2(5):213-219.

8. Rosen L, Ashurst H, Chap L. Targeting signal transduction pathways in metastatic breast cancer: A comprehensive review. Oncologist. 2010;15(3):216-235

9. Ande SR, Kommoju PR, Draxl S, et al. Mechanisms of cell death induced by L-amino acid oxidase, a major component of ophidian venom. Apoptosis. 2006;11(8):1439-1451.

10. Norbury CJ, Hickson ID. Cellular responses to DNA damage. Annu Rev Pharmacol Toxicol. 2001;41:367-401.

11. Rucavado A, Flores Sanchez E, Franceschi A, et al. Characterization of local tissue damage induced by LHF-II, a metalloproteinase withh weak hemorrhagic activity isolated from Lachesis muta muta snake venom. Toxicon. 1999;37(9):1297-1312.

12. Ferreira T, Camargo E, Ribela M, et al. Inflammatory Oedema induced by L. muta muta (Surucucu) venom and LmTX-I in the rat paw and dorsal skin. Toxicon. 2009;53(1):69-77.

13. Magalahaes A, Monteiro M, Magalahaes H, et al. Thrombin like enzyme from Lachesis muta muta venom: isolation and topographical analysis of its active site structure by means of the binding of amidines and guanidines as competitive inhibitors. Toxicon. 1991;35(10):1549-1559.

14. Jorge MT, Sano Martins IS, Tomy SC, et al. Snake bite by the bushmaster (Lachesis muta) in Brazil: case report and review of literature. Toxicon. 1997;35(4):545-554.

15. Tan N. L-amino acid oxidases and lactate dehydrogenase. In: Alaken, editor. Enzymes from snake venom. USA; 1998. p. 579-598. 
16. Zeller. A Snake venom action: Are enzymes involved in it? Experienta 1977;33(2):143-150.

17. Wie J, Yang H, Wie X, et al. Purification, characterization and biological activities of the L-amino acid Oxidase from Bungarus fasciatus snake venom. Toxicon. 2009;54(3):262-271.

18. Ehara T, Kitajima S, Kanzawa N, et al. Antimicrobial action of achacin is mediated by L-amina acid oxidase activity. FEBS Lett. 2002;531(3):509512.

19. Boer Lima P, Gontijo J, Da Cruz Hofling M. Histologic and functional renal alterations caused by Bothrops moojeni snake venom in rats. Am J Trop Med Hyg. 1999;61:698-706.

20. Ali S, Stoeva S, Abbasi A, et al. Isolation, structural and functiona characterization of an apoptosis inducing L-amino acid oxidase from leaf-nosed viper (Eristocophis macmahoni) snake venom. Arch Biochem Biophys. 2000;384(2):216-226.

21. Sun M, Guo C, Tian Y, et al. Biochemical, functional and structural characterization of Akbu LAAO: a novel snake venom L-amino acids oxidase from Agkistrodon blomhoffi ussurensis. Biochimie. 2010;92(4):343-349.

22. Ciscotto P, De Avila R, Coelho E, et al. Antigenic, microbial and parasitic properties of $\mathrm{L}$-amino acid oxidase isolated from Bothrops jararaca snake venom. Toxicon. 2009;53(3):330-341.

23. Rodrigues R, Da Silva J, Franca J, et al. Structural and functional properties of Bp-LAAO, a new L-amino acid oxidase isolated from Bothrops pauloensis snake venom. Biochimie. 2009;91(4):490-501.
24. Franca S, Kashima S, Roberto P, et al. Molecular approaches for structural characterization of Bothrops L-amino acid oxidases with antiprotozoal activity: cDNA cloning, comparative sequence analysis and molecular modeling. Biochem Biophys Res Commun. 2007;335(2):302-306.

25. Alves Paiva R, Figueiredo R, Antonucci G, et al. Cell cycle arrest evidence, parasiticidal and bactericidal properties induced by $\mathrm{L}$-amino acid oxidase from Bothrops atrox snake venom. Biochimie. 2011;93(5):941947.

26. Barnes L, Eveson J, Reichart P, et al. Pathology and genetics of head and neck tumors. USA: IARC Press; 2005. p. 113-119.

27. Van Engeland M, Ramaekers F, Schutte B, et al. A novel assay to measure loss of plasma membrane asymmetry during apoptosis of adherent cells in culture. Cytometry. 1996;24(2):131-139.

28. Samel M, Vija H, Ronnholm G, et al. Isolation and characterization of an apoptotic and platelet aggregation inhibiting L-amino acid oxidase from Vipera berus berus (common viper) venom. Biochim Biophys Acta. 2006;1764(4):707-714.

29. Suhr S, Kim D. Comparison of the apoptotic pathways induced by L-amino acid oxidase and hydrogen peroxide. J Biochem. 1999;125(2):305309.

30. Béroud C, Soussi T. The UMD- $\mathrm{p}^{53}$ database: new mutations and analysis tools. Hum Mutat. 2003;21(3):176-181. 